\title{
The effects of thermal shock in the early rearing period on performance, carcass characteristics and some blood parameters in broiler chickens
}

\author{
Abdolahad Shaddel-Tili, Mohammad Ghasemi-Sadabadi and Saeed Saemi Pesta-Bigelow \\ Department of Animal Science, Faculty of Animal Science and Veterinary Medicine, Shabestar Branch, Islamic \\ Azad University, Shabestar, Iran
}

\begin{abstract}
Article history
Received:10 Feb, 2016

Revised: 25 Mar, 2016

Accepted: 11 Apr, 2016

Abstract

The current study was carried out to evaluate the effects of thermal shock during the early rearing period on performance, carcass characteristics and some blood parameters in broiler chickens. A total of 240 Ross 308 broiler chickens was divided into 3 treatments, with 4 replicates containing 20 birds in each group. Experimental treatments were: group 1) not exposed to heat challenge (control), 2) sudden thermal shock and group and 3) gradual thermal shock. The result showed that the feed conversion ratio was significantly lower $(\mathrm{P}<0.05)$ in sudden thermal shock. In addition, carcass characteristics in this study were also markedly lower in the sudden thermal shock compared to the gradual thermal shock $(\mathrm{P}<0.05)$. Also, the thermal shock at early rearing period had no significant effect on blood parameters in this study. In conclusion, gradual thermal shock at early rearing period had a better effect on termotolerance compared to the sudden thermal shock in broiler chickens exposed to heat stress.

Keywords: sudden thermal shock, gradual thermal shock, termotolerance
\end{abstract}

\begin{abstract}
To cite this article: Shaddel-Tili A, M Ghasemi-Sadabadi and SS Pesta-Bigelow 2016. The effects of thermal shock in the early rearing period on performance, carcass characteristics and some blood parameters in broiler chickens. Res. Opin. Anim. Vet. Sci., 6(3): 78-83.
\end{abstract}

\section{Introduction}

In poultry science, much attention has been given to the behaviour and welfare of caged layers for egg production or to broilers raised for meat. Also, in poultry production, three different dimensions of the facility are heated, cooled and ventilated (Estevez and Christman, 2006). In recent years, heat stress effects on physiology of broiler chickens has been studied extensively (Ait-Boulahsen et al., 1989; Edens et al., 1992). Heat stress has major effects on decreased feed intake, growth rate, feed efficiency, and lower weight gain and increased fat deposition. Heat stress caused spend less time feeding, more time drinking and panting, as well as more time with their wings elevated, less time moving or walking, and more time resting (ElMoniary, 1991; Mack et al., 2013). Reilly et al. (1991), Estevez et al. (2002), Okelo et al. (2003) indicated that access to cool temperature have a positive effect on body weight, final carcass weight, feed efficiency and mortalities. Also, McDaniel et al. (1996) reported that high temperatures have a clear negative impact on fertility and growth performance.

For this purpose and predict of the dangerous effects of heat stress in broiler chickens, two management methods have been suggested to increase

\footnotetext{
*Corresponding author: Abdolahad Shaddel-Tili, Department of Animal Science, Faculty of Animal Science and Veterinary Medicine, Shabestar Branch, Islamic Azad University, Shabestar, Iran E-mail: shaddel_a@yahoo.com; Tel: +9842425311, Fax: +9842424927
} 
thermotolerance leading to the minimization of heatrelated mortality and to maintenance of productivity. So that, thermal shock at the early rearing period and adaptation of birds to heat challenge for increasing the thermotolerance potential of the broiler chickens were two important methods as a result of heat stress (Horowitz, 1998). Also, these methods have provided some suitable results in the economy and high growth rate in broiler chickens. So that, the early-age thermal shock has been used to reduce losses caused by heat stress (Arjona et al., 1988; Yahav and Hurwitz 1996; Yahav and Plavnik, 1999). It has been suggested that a temperature of $36-37.5^{\circ} \mathrm{C}$ at three days of age is optimum for early thermal conditioning of broilers (Yahav and McMurty, 2001). In similar studies, AitBoulahsen et al. (1995), Yahav and Hurwitz (1996), Yahav et al. (2004) suggested that thermal shock at early rearing period can be increased growth performance in broiler chickens. Halevy et al. (2001) showed that higher temperature at early rearing period increased the satellite cells counts that are very important for muscle tissue's hypertrophy. Early age thermal conditioning has been proposed as a technique to reinforce resistance of broiler chickens to heat stress during the finishing period (Yahav and Hurwitz, 1996; Zhou and Yamoto, 1997; Arjona et al., 1988; Yahav and Plavnik, 1999).

Therefore, the objectives of the present study were to evaluate the effects of thermal shock at the early rearing period on performance, carcass characteristics and some blood parameters in broiler chickens subjected to heat stress.

\section{Materials and Methods}

\section{Birds, experimental design and management}

A total of 240 one day old broiler chicks from the Ross 308 , was randomly allocated to 20 floor pens in a completely randomized design with 3 treatments, 4 replicates and 20 chicks in each replicate.

The experiment included three treatments: 1) an unexposed control group (T1), 2) sudden thermal shock (T2), and 3) gradual thermal shock (T3). Therefore, temperature in sudden thermal shock group was kept at $32 \pm 0.5^{\circ} \mathrm{C}$ from 1 to 5 days, $36 \pm 0.5^{\circ} \mathrm{C}$ from 5 to 6 day sand $32 \pm 1^{\circ} \mathrm{C}$ from 7 to 49 days of age. Also, temperature in gradual thermal shock groups were kept at $32 \pm 0.5^{\circ} \mathrm{C}$ on the first day of age, $33 \pm 0.5^{\circ} \mathrm{C}$ second day, $34 \pm 0.5^{\circ} \mathrm{C}$ third day, $35 \pm 0.5^{\circ} \mathrm{C}$ fourth day, $36 \pm$ $0.5^{\circ} \mathrm{C}$ fifth day, and $32 \pm 1^{\circ} \mathrm{C}$ from 6 to 49 days of age. The control group was not exposed to heat challenge during the trial period and the temperature was maintained according to Ross 308 strain catalogue.

In this experiment, feed and water were provided for ad libitum consumption. The diet, provided in mash form, was formulated according to the specifications of the National Research Council (1994). Diets were formulated using User Friendly Feed Formulation Done Again (UFFDA) according to nutritional suggestions. Composition of experimental diets is presented in Table 1. The basal diet was corn and soybean meal. All the chicks were kept under similar management conditions according to Ross 308 strain catalogue. Animal handling and experimental procedures were performed according to the Guide for the Care and Use of Laboratory animals by the National Institutes of Health (USA) and the current laws of the Iranian government for animal care.

\section{Performance}

Mean body weight gains, feed consumption and feed conversion ratios were calculated for each cage (replicate) between 1 and 49 days. Body weight gain was calculated and expressed as $\mathrm{g}$ per bird. Feed intake ( $g$ of feed intake/bird) over the entire growth period was calculated by totalling feed consumption in each time interval between each bird sampling. Feed conversion ratio ( $\mathrm{g}$ of feed intake /g of body weight gain) was calculated by dividing total feed intake by total weight gain in each cage.

Table 1: Composition and calculated nutrient content of broilers during the experiment

\begin{tabular}{lccc}
\hline Ingredients (\%) & \multicolumn{3}{c}{ Diets } \\
\cline { 2 - 4 } & Starter & Grower & Finisher \\
\hline Corn & 54 & 60.46 & 65.50 \\
Soybean meal (44\% CP) & 35.77 & 30 & 23 \\
Wheat & 0 & 0.8 & 7.7 \\
Dicalcium phosphate & 2.4 & 1 & 1 \\
Oyster shell & 1.5 & 1.5 & 1.5 \\
DL- Methionine & 0.31 & 0.20 & 0.26 \\
L-Lysine mono hydro chloride & 0.22 & 0.22 & 0.22 \\
Wheat bran & 5 & 5 & 0 \\
Mineral premix b & 0.3 & 0.3 & 0.3 \\
Vitamin premix & 0.3 & 0.3 & 0.3 \\
Common salt & 0.2 & 0.2 & 0.2 \\
\hline Calculated Analysis & \multicolumn{3}{|c}{} \\
\hline ME (kcal/kg) & 2930 & 3015 & 3165 \\
Crud protein (\%) & 22 & 19.6 & 19.1 \\
Calcium (\%) & 1 & 0.97 & 0.92 \\
Available phosphorus (\%) & 0.3 & 0.43 & 0.40 \\
Methionine (\%) & 0.54 & 0.48 & 0.39 \\
Lysine (\%) & 0.12 & 1.10 & 0.86 \\
\hline
\end{tabular}

${ }^{a}$ Vitamin and mineral premix supplied the following per kilogram of diet: vitamin A (from vitamin A acetate), 10000 IU; vitamin D3, $9790 \mathrm{IU}$; vitamin E (dl-tocopheryl acetate), $30 \mathrm{IU}$; vitamin B12, $20 \mu \mathrm{g}$; Riboflavin, $4.4 \mathrm{mg}$; calcium pantothenate, $40 \mathrm{mg}$; niacin, $22 \mathrm{mg}$; choline, $840 \mathrm{mg}$; biotin, $30 \mu \mathrm{g}$; thiamin, $4 \mathrm{mg}$; zinc sulfate, $60 \mathrm{mg}$; copper sulfate, 100 $\mu \mathrm{g}$; selenium (sodium selenate), $0.2 \mathrm{mg}$; iodine, $1 \mathrm{mg}$; manganese oxide, $60 \mathrm{mg}$; ${ }^{\mathrm{b}}$ Provided the following per kilogram of diet: Mn, $99.2 \mathrm{mg}$; Fe, $50 \mathrm{mg}$; Zn, $84.7 \mathrm{mg}$; Cu, $10 \mathrm{mg}$; I, $0.99 \mathrm{mg}$; Se, $0.2 \mathrm{mg}$; Choline chloride, $250 \mathrm{mg}$. 


\section{Carcass characteristics}

At 42 days, four chicks from each group were selected and were killed by neck dislocation and dissected manually, then relative weights of different body organs were recorded including live body weight, eviscerated carcass, liver, bursa of Fabricius, gizzard, breast and thigh yield and expressed as a percentage of body weight.

\section{Blood sample}

Blood samples were collected from the wing vein and centrifuged at $750 \times \mathrm{g}$ for 10 minutes and plasma was separated and stored at $-20^{\circ} \mathrm{C}$ until used. Serum glucose, triglyceride and total protein levels were determined with kits (Pars Amazon, Iran) by colorimetric method using an auto analyzer (MindrayBS-200, Germany). Half of the blood samples were drained into tubes with anticoagulant (EDTA $1 \mathrm{mg} / \mathrm{ml}$ blood). Erythrocytes and leukocyte counts were determined by using a haemocytometer according to Natt and Herrick (1952), packed cell volume (PCV) was determined using haematocrit tubes.

\section{Statistical analysis}

All the data were subjected to ANOVA procedures for completely randomized designs using the general linear model (GLM) procedure of the SAS program
(SAS, 2003). Data in percentages were transformed by Arcsin-square-root. Differences between treatments were compared by the turkey's multiple range tests following ANOVA, and values were considered statistically different at $\mathrm{P}<0.05$ ).

\section{Results}

The effects of thermal shock in the early rearing period on weight gain, feed intake and feed conversion ratio in broiler chickens subjected to heat stress are shown in Table 2. According to the result of this study, there were no significant effects on body weight gain and feed intake at the end of the experiment. Feed conversion ratio was significantly $(\mathrm{P}<0.05)$ better in gradual thermal shock groups compared to the sudden thermal shock. The effects of thermal shock in the early rearing period on carcass characteristic in broiler chickens subjected to heat stress are shown in Table 3. Generally, the result of this experiment showed that sudden thermal shock at early rearing period indicated lower carcass yield, liver and bursa compared to the gradual thermal shock in broiler chickens exposed to heat stress, while, gradual thermal shock at the early rearing period showed higher gizzard and breast weight than sudden thermal shock and control groups $(\mathrm{P}<0.05)$. Also, the comparison of thermal shock during the early

Table 2: Effects of thermal shock during the early rearing period on body weight gain (BWG), feed intake (FI) and feed conversion ratio (FCR) in broiler chickens subjected to heat stress

\begin{tabular}{lccc}
\hline Treatment & \multicolumn{3}{c}{$1-49$ day of age } \\
\hline Control & Body weight gain $(\mathrm{g})$ & Feed intake $(\mathrm{g})$ & Feed conversion ratio $(\mathrm{g} / \mathrm{g})$ \\
Gradual thermal shock & 2881.8 & 5465.24 & $1.89^{\mathrm{b}}$ \\
Sudden thermal shock & 2899.8 & 5448.50 & $1.87^{\mathrm{b}}$ \\
\hline SEM & 2815.5 & 5458.75 & $1.93^{\mathrm{a}}$ \\
P-Value & 82.18 & 92.175 & 0.051 \\
\hline a-b Averages in a column with different superscript letters are significantly different $(\mathrm{P}<0.05)$ & 0.0003 \\
\hline
\end{tabular}

$\mathrm{a}-\mathrm{b}$ Averages in a column with different superscript letters are significantly different $(\mathrm{P}<0.05)$.

Table 3: Effects of thermal shock during the early rearing period on carcass characteristic in broiler chickens subjected to heat stress (\% of live body weight)

\begin{tabular}{lcccccc}
\hline Treatment & Carcass yield (\%) & Liver (\%) & Gizzard (\%) & Bursa (\%) & Breast yield (\%) & Thing yield (\%) \\
\hline Control & $74.70^{\mathrm{a}}$ & $3.09^{\mathrm{a}}$ & $2.50^{\mathrm{a}}$ & $0.45^{\mathrm{a}}$ & $27.71^{\mathrm{b}}$ & $20.97^{\mathrm{b}}$ \\
Gradual thermal shock & $74.98^{\mathrm{a}}$ & $3.10^{\mathrm{a}}$ & $2.54^{\mathrm{a}}$ & $0.46^{\mathrm{a}}$ & $29.84^{\mathrm{a}}$ & $23.51^{\mathrm{a}}$ \\
Sudden thermal shock & $72.18^{\mathrm{b}}$ & $3.03^{\mathrm{b}}$ & $2.40^{\mathrm{b}}$ & $0.38^{\mathrm{b}}$ & $27.15^{\mathrm{b}}$ & $23.50^{\mathrm{a}}$ \\
\hline SEM & 3.76 & 0.01 & 0.017 & 0.0004 & 1.2 & 1.42 \\
P-Value & 0.03 & 0.0022 & 0.0002 & 0.001 & 0.0004 & 0.0078 \\
\hline
\end{tabular}

${ }^{\mathrm{a}-\mathrm{c}}$ Averages in a column with different superscript letters are significantly different $(\mathrm{P}<0.05)$.

Table 4: Effects of thermal shock during the early rearing period on some blood parameters in broiler chickens subjected to heat stress

\begin{tabular}{lcccccc}
\hline Treatment & RBCs $\left(\times 10^{6} / \mu \mathrm{l}\right)$ & WBCs $\left(\times 10^{3} / \mu \mathrm{l}\right)$ & PCV $(\%)$ & Glucose $(\mathrm{mg} / \mathrm{dl})$ & Triglyceride $(\mathrm{mg} / \mathrm{dl})$ & TP $(\mathrm{g} / \mathrm{dl})$ \\
\hline Control & 2.14 & 26.76 & 33.37 & 191.30 & 78.75 & 3.53 \\
Gradual thermal shock & 2.37 & 28.76 & 33.87 & 194.31 & 81.25 & 4.19 \\
Sudden thermal shock & 2.56 & 26.77 & 33.25 & 188.29 & 81.37 & 4.19 \\
\hline SEM & 0.095 & 0.709 & 0.51 & 5.29 & 4.20 & 0.42 \\
P-Value & 0.360 & 0.33 & 0.67 & 0.77 & 0.34 & 0.48 \\
\hline
\end{tabular}

${ }^{\mathrm{a}-\mathrm{b}}$ Average in a column with different superscript letters are significantly different $(\mathrm{P}<0.05)$. 
rearing period and control groups did not show significant difference in carcass yield, liver, bursa and gizzard in broiler chickens $(\mathrm{P}<0.05)$.

The effects of thermal shock in the early rearing period on some blood parameters at whole period in broiler chickens subjected to heat stress are shown in Table 4. Furthermore, in this experiment haematological and biochemical parameters were not markedly altered in the thermal shock at early rearing period $(\mathrm{P}>0.05)$. The results of blood parameters indicated that gradual thermal shock showed numerically higher WBCs counts, PCV and glucose, while triglyceride, RBCs counts were lower compared to the sudden thermal shock in broiler chickens exposed to heat stress at the end of the experimental period.

\section{Discussion}

By examining the results obtained, it can be concluded that thermal shock during the early rearing period had a higher feed intake compared to control group in broiler chickens exposed to heat stress at 6 to 49 days. Also, gradual thermal shock at early rearing period showed significantly lower feed intake than control groups. This fact is already known that thermal shock at early rearing period caused increased thermotolerance in broiler chickens (Rahimi et al., 2001; Zhou and Yamoto, 1997; Yahav and Mcmurty, 2001).

Yahav and Plavnik (1999) did not observe a significant reduction in body weight gain compared to the control. Thus, it appears that effect of thermal shock during the early rearing period on body weight gain in broiler chickens is inconsistent. Yahav and Hurwitz (1996) reported that exposure to thermal shock during early rearing period proved to be ineffective in reinforcing the effects of thermal condition on resistance to heat stress. One of the other mechanisms of thermotolerance is the ability to reduce heat production, which is regulated to a large extent by triiodothyronine hormone (McNabb and King, 1993). The high growth performance in a gradual thermal shock group than the sudden thermal shock group was due to the physiological mechanisms involved in the induction of thermotolerance in an early-life thermal exposure (Yahav and Hurwitz, 1996).

In similar results, Rudas and Pethes (1984), Williamson et al. (1985) reported that one of the important factors to improve thermotolerance is achieved by an early age conditioning involving modulation in thermal production through changes in circulating triiodothyronine hormone.

In same case, Yahav and Hurwitz (1996) showed that reduced triiodothyronine hormone and hemodynamic changes may be part of the mechanism associated with improved thermotolerance by thermal shock at early rearing period. Arjona et al. (1988) showed that thermal shock at early rearing period improved thermotolerance without reducing growth performance in broiler chickens.
The higher relative growth rate in parallel with a better feed conversion ratio as a result of heat shock induction in the early growth phase has been reported by others (Zhou and Yamoto, 1997; Yahav and McMurty, 2001). De Basillio et al. (2001) reported that early thermal shock significantly improved carcass yield at the end of the rearing period. In this experiment, it seems that high carcass yield, gizzard, liver, breast and thing weight in thermal shock can be related to the high body weight gain as results of higher thermotolerance in gradual thermal shock than sudden thermal shock in under heat stress broiler chickens.

In same results, Arjona et al. (1988), Yahav and Plavnik (1999) suggested that thermal shock at early rearing period improved body weight in response to subsequent heat challenge in broiler chickens. Also, in contrast with our finding, Morsy (2013) showed that thermal shock during the early rearing period had no significant effect on final carcass yield and liver weight. Rahimi (2005) reported that thermal shock at early rearing period improved performance in broiler chickens. The high carcass yield in gradual thermal shock in this study may be the stimulation of muscle growth by increasing the satellite cell myogenic process in young chicks (Halevy et al., 2001).

In this experiment, bursa of Fabricius showed higher weight in gradual thermal shock groups than other groups. In similar case, Liew et al. (2003) concluded that the combination of heat conditioning at an early age could improve weight gain and resistance in broilers under heat stress at rearing period. Also, they suggested that the improved thermal tolerance and disease resistance in these birds could be attributed to better thermal shock protein response. In the same case, Zulkifli and Norma (1999) showed that heat challenge had no significant effect on blood parameters in birds.

In the present study, the haematological parameters were not different between groups, but in contrast with our finding, Yahav and Hurwitz (1996) found that thermal shock at early rearing period resulted in a significant change in haematological parameters. Nagwa et al. (2012) reported that, haematological parameters were decreased under heat stress and increased in acclimated chicken compared with un-acclimated birds. On the other hand, the low counts of haemoglobin and packed cell volume recorded in heat stress (Oladele et al., 2001).

\section{Conclusion}

The results of this study showed that gradual thermal shock at early rearing period had higher effect on termotolerance compared to the sudden thermal shock in broiler chickens.

\section{Acknowledgements}

This article is a part of M.Sc. thesis in Animal Science, Islamic Azad University of Shabestar Branch (thesis supervisors: Dr. Abdolahad Shaddel-Tili). 


\section{References}

Ait-Boulahsen A, Garlich JD, Edens FW (1989) Effect of fasting and acute heat stress on body temperature, blood acid-base and electrolyte status in chickens. Comp Biochem Phys 94: 683-687.

Ait-Boulahsen A, Garlich JD, Edens FW (1995) Potassium chloride improves the thermotolerance of chickens exposed to acute heat stress. Poult Sci 74: 75-87.

Arjona AA, Denbow DM, Weaver WDJr (1988) Effect of heat stress early in life on mortality of broilers exposed to high environmental temperatures just prior to marketing. Poult Sci 67: 226-231.

De Basillio V, Vilarino M, Yahav S, Picards M (2001) Early age thermal conditioning and a dual feeding program for male broilers challenged by heat stress. Poult Sci 80: 29-36.

Edens FW, Hill CH, Wang S (1992) Heat shock protein response in phosphorous-deficient heat stressed broiler chickens. Comp Biochem Phys 103: 827-831.

El-Moniary MMA (1991) Studies on broiler feeding in the subtropics". Ph. D. Thesis, Ain shams University, Fac. Of Agaric, Egypt.

Estevez I, Christman MC (2006) Analysis of the movement and use of space of animals in confinement: the effect of sampling effort. App Anim Behavior Sci 97: 221-240.

Estevez I, Tablante N, Pettit-Riley RL, Carr L (2002) Use of cool perches by broiler chickens. Poult Sci 81: 62-69.

Halevy O, Krispin A, Leshem Y, McMurtry J, Yahav S (2001) Early age heat stress accelerates skeletal muscle satellite cell proliferation and differentiation in chicks. Am J Physiol 281: 302-309.

Horowitz M (1998) Do cellular heat acclimation responses modulate central thermoregulatory activity? News Physiol Sci 13: 218-226.

Liew PK, Zulkifli I, Hair-Bejo M, Omar AR, Israf DA (2003) Effects of early age feed restriction and heat conditioning on heat shock protein 70 expression, resistance to Infectious Bursal Disease and growth in male broiler chickens subjected to heat stress. Poult Sci 82: 1879-1885.

Mack LA, Felver-Gant JN, Dennis RL, Cheng HW (2013) Genetic variation alter production and behavioral responses following heat stress in 2 strains of laying hens. Poult Sci 92: 285-294.

McDaniel CD, Bramwell RK, Howarth B (1996) The male contribution to broiler breeder heat-induced infertility as determined by sperm-egg penetration and sperm storage within the hen's oviduct. Poult Sci 75: 1546-1554.

McNabb FM, king DB (1993) Thyroid hormones effects on growth, development and metabolism. In "The endocrinology of growth development and metabolism in vertebrates", Eds. Schreibman, M., Scanes, C. and Pang, P. Academic press, USA.393 pp.

Morsy AS (2013) Effect of heat shock exposure on the physiological responses and semen quality of male chickens under heat stress conditions. Egypt poult Sci 33: 143-161.

Nagwa AA, Hassan AM, Mehaisen GMK, Emam KRS (2012) Effect of using heat shock programs on thermoregulation responses and performance of laying hens under desert conditions. Egypt Poult Sci 32: 777-790.

National Research Council (1994) Nutrient requirements of poultry. 9th edition National Academy Press Washington, D.C., U.S.A.

Natt MP, Herrick CA (1952) A new diluent for counting the erythrocytes and leukocytes for the chicken. Poult Sci 31: 735-737.

Okelo RO, Carr LE, Harrison PC, Douglass LW, Byrd VE, Wabeck CW, Schreuders PD, Wheaton FW, Zimmermann NG (2003) Effectiveness of a novel method to reduce heat stress in broilers: a cool roost system. Am Soc Agric Eng 46: 1675-1683.

Oladele SB, Ogundipe S, Ayo JO, Esievo KAN (2001) Effect of season and sex on packed cell volume, hemoglobin and total proteins of indigenous pigeons in Zaria, Northern Nigeria. Vet Arhiv 71: 277-286.

Rahimi G (2005) Effect of Heat Shock at Early Growth Phase on Glucose and Calcium Regulating Axis in Broiler Chickens. Int J Poult Sci 4 (10): 790-794,

Rahimi G, Sayyazadeh H, and Saadat D (2001) The effect of heat shock at early growth phase to improve thermotolerance and performance in broiler chickens. J Agr Sci Nat Res 3: 154-160.

Reilly WM, Koelkebeck KW, and Harrison PC (1991) Performance evaluation of heat stressed commercial broilers provided water-cooled floor perches. Poult Sci 70: 1699-1703.

Rudas P, Pethes G (1984) Studies on the conversion of thyroxin to $3,5,3$ '-triiodothyronine in normal and thyroidectomies chickens. Gen Comp Endocrinol 54: 154-161.

SAS Institute. SAS Users guide: Statistics. Version 6.12. SAS Institute Inc., Cary, NC, 2003.

Williamson RA, Misson BH, Davison TF (1985) The effect of exposure to $40 \mathrm{C}$ on the heat production and the serum concentrations of triiodothyronine, thyroxin and corticosterone in immature domestic fowl. Gen Comp Endocrinol 60: 78-186.

Yahav S, Plavink I (1999) Effect of early age thermal condition and food restriction on performance and thermotolerance of male broiler chickens. $\mathrm{Br}$ poult Sci 40: 120-126.

Yahav S, McMurty J (2001) Thermotolerance acquisition in broiler chickens by temperature conditioning early 
in life: The effect of timing and ambient temperature. Poult Sci 80: 1662-1666.

Yahav S, Straschnow A, Plavnik I, Hurwitz S (1996) Effect of diurnally cycling versus constant temperatures on chickens growth and food intake. $\mathrm{Br}$ Poult Sci 37: 43-54.

Yahav S, Hurwitz S (1996) Induction of thermotolerance in male broiler chickens by temperature conditioning at an early age. Poult Sci 75: 402-406.

Yahav S, Sasson S, Rath, Shinder D (2004) The effect of thermal manipulation during embryogenesis of broiler chicks (Gallus domestics) on hatchability, body weight and thermoregulation after hatch. J Theor Biol 29: 245- 250.

Zhou WT, Yamoto S (1997) Effect of environmental temperature and heat production due to food intake and abdominal temperature, skin temperature and respiration rate in broilers. Br Poult Sci 38: 107- 114.

Zulkifli, I, Che Norma RT (1999) Acute heat-stress effect on physiology and fear-related behavior in red jungle fowl and domestic fowl. Can J Anim Sci 79: 165170. 